\title{
Hakemler İçin Mesleki Haz Ölçeği: Geçerlik ve Güvenirlik Çalışması-HiMHÖ
}

\author{
Aydın KARAÇAM ${ }^{1}$ \\ Atilla PULUR ${ }^{2}$
}

${ }^{1}$ Mamak Ali Şir Nevai Ortaokulu, ANKARA
${ }^{2}$ Gazi Üniversitesi Spor Bilimleri Fakültesi, ANKARA

Künye: Karaçam, A. ve Pulur, A. ( 2018). Hakemler İçin Mesleki Haz Ölçeği: Geçerlik ve Güvenirlik ÇalışmasıHIMHÖ. Gaziantep Üniversitesi Spor Bilimleri Dergisi 3(2): 35-45.

\section{Öz}

Çalışmanın amacı Mesleki Haz Ölçeği'nin hakemler için uyarlama çalışmasının yapılmasıdır. Çalışma grubu uygun örnekleme yöntemi ile oluşturulmuştur. Çalışmanın örneklemini 2016-2017 sezonunda aktif hakemlik yapan 314 kişilik hakem grubu oluşturmuştur. Bu hakemlerin \%36 (n:113) basketbol, \%33 (n:106) futbol, \%5 (n:16) tekerlekli sandalye basketbol, \%10 (n:31) hentbol, \% 10 (n:30) voleybol ve \% 6 (n:18) tenis hakemidir. Araştırmaya katılan hakem grubunun \%14'ünü (n:44) kadın, \% 86'sını ( $\mathrm{n}: 270)$ erkek hakemler oluşturmaktadır. Araştırmaya katılan hakemlerin yaş ortalaması 26, hakemlik tecrübeleri ortalama 6 yıldır. Araştırmaya katılan hakemlere ölçek müsabakalarının olmadığı bir zamanda yüz yüze uygulanmıştır. Verilerin çözümlenmesi SPSS 21 ve AMOS programları kullanılarak yapılmıştır. Ölçeğin yapı geçerliği için temel bileşenler analizi ve varimax döndürme teknikleri kullanılmıştır. HiMHÖ'nün ölçüt geçerliğini ve madde ayırt ediciliğini belirlemek için pearson momentler çarpımı korelasyon katsayısı ve t-testi kullanılmıştır. Açımlayıcı faktör analizi sonucunda toplam açıklanan varyansın \%50.59 olduğu ve maddelerin tek faktör altında toplandığı görülmüştür. Ölçek için alfa iç tutarlık kat sayı .83 ve KMO değerinin .85 olduğu görülmüştür. Ölçeğe uygulanan DFA analizi sonucunda $\chi^{2} / \mathrm{sd}=1.636 \mathrm{RMSEA}=.07$, $\mathrm{CFI}=.96, \mathrm{GFI}=.94, \mathrm{AGFI}=.90, \mathrm{RMR}=.01$ ve $\mathrm{NFI}=.92$ olduğu görülmüştür. HiMHÖ'nün madde toplam korelasyonlarının .56 ile .84 arasında değişiklik gösterdiği ve $t$-değerlerinin tüm maddelerde anlamlı olduğu saptanmıştır $(p<.001)$. Sonuçlar HíMHÖ ölçeğinin hakemlerin mesleki haz düzeylerini ölçmede geçerli ve güvenilir olduğunu göstermektedir.

Anahtar Kelime: Hakem, Mesleki Haz, Ölçek, Geçerlik, Güvenirlik

\section{Orijinal Makale}

\section{Yayın Bilgileri}

Gönderi Tarihi: 18.04.2018

Kabul Tarihi: 30.05.2018

Yayın Tarihi: 20.06.2018

\section{Sorumlu Yazar}

e-mail: aydinkaracam@gmail.com

DOI: $10.31680 / g a u n j s s .416737$

\section{The Zest for Work Scale for Referees: Validity and Reliability Study-ZWSR}

\begin{abstract}
The aim of the study is to adaptation study of the Zest for Work Scale for Referees. The study group was formed by convenience sampling method. The sample of the study is consisted of 314 referees who actively served during the $2016-2017$ season. Participants are consisted of referees of basketball $(36 \%, n=113)$, soccer $(33 \%, n=106)$, wheelchair basketball $(5 \%, n=16)$, handball $(\% 10, n=31)$, and $(6 \%, n=18)$ tennis. $14 \%$ $(n=44)$ of participants are female and $86 \%$ of them $(n=270)$ are male referees. The average age of the referees participating in the study is 26 , and the average year of refereeing is 6 . The scale was administered to the referees by face-to-face at a time when they were not in charge in a match. The analysis of the data was conducted using SPSS 21 and AMOS programs. Principal component analysis and varimax rotation techniques were used for construct validity of the scale. The Pearson Product-Moment Correlation Coefficient and the t-test were used to determine the criterion validity and item discrimination of the ZWSR. As a result of the exploratory factor analysis, it was observed that the total variance explained is $50.59 \%$ and the items are clustered under a single factor. The Cronbach's alpha coefficient for internal consistency of the scale is .83 and the KMO value is .85 . The DFA analysis of the scale showed $\chi^{2} / \mathrm{sd}=1.636$ $\mathrm{RMSEA}=.07, \mathrm{CFI}=.96, \mathrm{GFI}=.94, \mathrm{AGFI}=.90, \mathrm{RMR}=.01$ and $\mathrm{NFI}=.92$. The item total correlations of the ZWSR vary between .56 and .84 , and t-values are significant for all items $(p<.001)$. The results show that the ZWSR is valid and reliable in measuring the level of referees' zest for work.
\end{abstract}

\section{Original Article}

Article Info

Received: 18.04 .2018 Accepted: 30.05 .2018 Published: 20.06.2018

\section{Corresponding Author}

e-mail: aydinkaracam@gmail.com 


\section{Giriş}

Hakemler için mesleki haz kavramı pozitif psikolojiden inşa edilmiş bir kavramdır. Hakemler için mesleki haz kavramı, hakemlerin hakemlik mesleğine yönelik duydukları ilgi, coşku, mutluluk, canlılık ve heyecan gibi olumlu duygusal hisleri içeren bir kavramdır.

Tüm meslekler için haz fikri işle ilişkilendirilebilmekte ve haz, iş doyumu ve yaşam doyumunu öngörmektedir (Hoy ve Tarter, 2011). İş doyumu, bireyin işinden veya iş deneyimlerinden kaynaklanan keyifli veya olumlu duygusal durum olarak tanımlanmaktadır (Lent ve Brown, 2006). Yaşam doyumundan ise genel anlamda iyi hissetme duygusu olarak bahsedilebilmektedir (Lent ve ark., 2011). Peterson ve Seligman'ın (2004) iyi karakterin özelliklerinin belirlenmesi amacıyla yaptıkları sınıflamada haz, hayata umut, enerji ve heyecanla yaklaşmak olarak belirlenmiştir. Park ve Peterson'a (2010) göre haz, hayata heyecan ve enerjiyle yaklaşmak, bir şeyleri yarım veya gönülsüzce yapmamak, hayatı bir macera olarak görerek yaşamak ve kendini canlı ve aktif hissetmek anlamına gelmektedir.

Mesleki haz kavramını iş doyumundan ayıran özelliği canlılık içermesidir. Canlılık; mutluluk, ilgi ve coşkuyu içeren birtakım pozitif duygularla ilişki içindedir. Canlılık yüksek düzeyde aktivasyon veya enerji içermesi yönüyle iyi hissetmeden ve mutluluktan ayrılmaktadır (Weinstein ve Ryan, 2009). Josepshon ve Vingard'a (2007) göre mesleki haz kavramı yaşam hazzı kavramından türemekte ve mevcut çalışma durumundan duyulan coşku ve doyumun derecesi anlamına gelmektedir. Mesleki haz kavramı, iş doyumundan daha geniş bir kavram olarak yorumlanabilmekte ve memnuniyetin yanında coşku ve iş doyumuna ilişkin daha güçlü duyguları içermektedir. Çalışanların mesleklerinden duydukları hazzın geliştirilmesi ve teşvik edilmesi, çalışanların işe meslek aşkıyla yaklaşmalarını sağlayacak ve iş doyumları ile üretkenliklerini destekleyecektir (Sezgin ve Erdoğan, 2015). Bu bağlamda hakemlerin hakemlik mesleğinden duydukları haz düzeylerinin bilinmesi önem arz etmektedir.

Hakemler, müsabaka sırasında görevlerini başarıyla yerine getirmek ve kararlarında hata yapmamak için baskı altında birden fazla görevi yerine getirmek zorundadır. Örneğin, hakemler, olumsuz koşullar ve baskı altında, maç sırasında gerçekleşen eylemleri değerlendirmeli ve yargılamalı, hızlı kararlar almalı, oyunu yönetmeli, doğru iletişim kurmalı, oyunun birden çok yönüne dikkat etmeli, düzenini sürdürmeli, anlaşmazlıkları ve problemleri çözmelidir (Tuero ve ark., 2002; Karaçam 
\& Pulur, 2016). Bu görevlerdeki yetersizlik, dikkatsizlik, yanlış kararlar, gecikmeli tepkiler, nihai stres ve tükenmişliğe yol açabilir (Guillén ve Feltz, 2011; Ekmekçi, 2008; Ekmekçi, 2016). Ayrıca hakemler özellikle popüler spor branşlarında müsabaka öncesi, sırası ve sonrasında seyirci, oyuncu ve kulüp baskısına maruz kalmaktadırlar. Bu nedenle hakemlerin yaptıkları iş oldukça zor ve yıpratıcıdır. Hakemler tüm bu olumsuz etkenlere karşı güçlü bir karakter göstermek zorundadır. Peterson ve ark., (2009) göre haz, içsel veya dışsal engeller karşısında hedeflere ulaşabilmek için içinde irade barındıran duygusal bir karakter özelliği olarak ortaya çıkmaktadır. Yaptığı işten haz alan hakemlerin bu içsel veya dışsal engelleri ve olumsuzlukları daha rahat aşarak üst düzeyde performans gösterecekleri düşünülmektedir. Bu nedenle hakemlerin mesleki haz düzeylerinin ölçülmesi önem arz etmektedir.

Bu nedenle çalışmada hakemlerin hakemlik mesleğinden duydukları hazzın ölçülebilmesi için Mesleki Haz Ölçeği hakemler için uyarlanarak geçerlik ve güvenirlik çalışmasının yapılması amaçlanmıştır.

\section{Yöntem}

\section{Araştırma grubu}

Bu araştırmada araştırma grubu uygun örnekleme yöntemi ile oluşturulmuştur. Ulaşılabilirlik ve elverişlilik esasına dayalı olan uygun örnekleme yöntemi bazı araştırma konularında bilgilerin hızlıca toplanması amacıyla tercih edilen bir yöntemdir (Büyüköztürk, 2010a). Uygun örnekleme yöntemiyle seçilen 314 kişilik grubu \%36 (n:113) basketbol, \%33 (n:106) futbol, \%5 (n:16) tekerlekli sandalye basketbol, \%10 (n:31) hentbol, \% 10 (n:30) voleybol ve \% 6 (n:18) tenis hakemi oluşturmaktadır. Araştırmaya katılan hakem grubunun \%14'ü (n:44) kadın, \% 86'sı (n:270) erkek hakemler oluşturmaktadır. Araştırmaya katılan hakemlerin yaş ortalanması 26, hakemlik tecrübeleri ortalama 6 yıldır. Araştırmaya katılan hakemlere ölçek müsabakalarının olmadığı bir zamanda yüz yüze uygulanmıştır.

\section{Veri toplama araçları}

\section{Hakemler İçin Mesleki Haz Ölçeği (HiMHÖ)}

İşlem

Hakemler için mesleki haz ölçeği için Erdoğan (2013) tarafından geliştirilen Mesleki Haz Ölçeği (MHÖ) temel alınmıştır. MHÖ ölçeğinin 7 maddeden oluşan tek 
boyutlu yapısı üzerinden ölçek maddeleri araştırmacı tarafından hakemlere uyarlanmıştır. Araştırmacı tarafından belirlenen 7 maddelik taslak form üst klasmanlarda hakemlik yapmış iki akademisyen, iki üst düzey hakem, mesleki haz üzerine çalışması olan bir akademisyen ve bir ölçek geliştirme uzmanına ileti yoluyla gönderilerek ölçek maddelerinin uygun olup olmadığı konusunda uzman görüşü alınmıştır. Uzmanlardan alınan görüş ve öneriler doğrultusunda taslakta yer alan maddelerin hakemlerin mesleki haz düzeylerini belirlemede yeterli olduğu, madde eklemeye veya çıkarmaya gerek olmadığı görülmüştür. Buradan hareketle 7 maddelik taslak form nihai form olarak kabul edilmiştir.

\section{Verilerin analizi}

$\mathrm{Bu}$ araştırmada öncelikle tüm katılımcılara çalışmanın amacı hakkında bilgi verilmiştir. Verilerin çözümlenmesi SPSS 21 ve AMOS programları kullanılarak yapılmıştır. Verilerin analizinde öncelikli olarak veri seti hatalı değer, aykırı değer, normallik ve çoklu bağıntı açısından incelenmiştir. Bu süreçte yanlışlıkla hatalı olarak girilen veri olmadığı gözlenmiştir. Geçerlik ve güvenirlik analizleri kapsamında ölçeğin faktör yapısını incelemek amacıyla verilere açımlayıcı faktör analizi (AFA) yapıımıştır. AFA sonucunda öz değeri 1'den büyük olan faktörler üzerinde işlem yapılmıştır (Eroğlu, 2009). Ölçeğin güvenirliği için alfa iç tutarlık katsayısı hesaplanmıştır. AFA sonucunda oluşan yapının ne ölçüde uygun olduğunu belirlemek amacıyla verilere AMOS programı kullanılarak doğrulayıcı faktör analizi (DFA) uygulanmıştır. Bu analizde birçok doğrulayıcı uyum indeksi kullanılmaktadır. Ki-kare/serbestlik derecesi uyum indeksinin 5 'ten küçük olması orta düzeyde, 2.5 'ten küçük olması mükemmel uyumu göstermektedir (Çokluk ve ark., 2010). RMSEA (Root Mean Square Error of Approximation) uyum indeksinin .06'dan küçük olması modelin mükemmel uyumlu olduğunu, .10'dan küçük olması uyum düzeyinin kabul edilebilir olduğunu göstermektedir. NFI (Normed Fit Index) ve CFI (Comparative Fit Index) uyum indekslerinin .95'e eşit veya büyük olması modelin uyumunun iyi olduğunu göstermektedir (Thomson, 2004). GFI (Goodness of Fit Index) ve AGFI (Adjusted Goodness of Fit Index) uyum indekslerinin .90 ve üzerinde olması iyi bir uyumun göstergesi olarak kabul edilmektedir (Raykov ve Marcoulides, 2000). RMR (Root Mean Square Residuals) uyum indeksinin .05 'ten küçük olması da iyi bir uyumun göstergesidir (Çokluk ve ark. 2010). Ölçeğin madde ayırt ediciliğini belirlemek için pearson momentler çarpımı korelasyon katsayısı ve t-testi kullanıımıştır. 


\section{Bulgular}

\section{HÖYÖ’nün Geçerlik ve Güvenirlik Çalışmasına İlişkin Bulgular}

\section{Açımlayıcı Faktör Analizi (AFA)}

Büyüköztürk (2010b) verilerin faktör analizine uygun olup olmadığını Kaiser Meyer Olkin (KMO) katsayısı ve Barlett (Sphericity) Küresellik testi kullanılarak belirlenebileceğini belirtilmiştir. Bazı araştırmacılar faktör analizi için KMO katsayısının örneklem büyüklüğü için değerinin .80 - .90 arasında olmasının iyi ve Barlet sphericity testinin .05 düzeyinde anlamlı çıkması gerektiğini belirtmektedir (Çokluk, Şekercioğlu ve Büyüköztürk, 2010; Leech ve ark., 2005). KMO katsayısının .85 ve Barlett Sphericity testi sonucunun $X 2=295,474, \mathrm{df}=21,(p<.00)$ istatistiksel olarak anlamlı bulunması verilerin faktör analizine uygun olduğunu göstermektedir. HİMHÖ'nün faktör analizi sonuçları Tablo 1'de verilmiştir.,

Tablo 1. HÖYÖ’nün Faktör Analizi Sonuçları

\begin{tabular}{ccc}
\hline Madde no & Faktör ortak varyansı & Faktör yük değeri \\
\hline 1 & .63 & .79 \\
2 & .64 & .80 \\
3 & .72 & .85 \\
4 & .58 & .76 \\
5 & .33 & .50 \\
6 & .31 & .46 \\
7 & .59 & .76 \\
\hline
\end{tabular}

Açıklanan toplam varyans: \% 50.59

Cronbach alpha: .83

Açımlayıcı faktör analizi sonucunda toplam açıklanan varyansın \%50.59 olduğu saptanmıştır. Bu bulgu ölçeğin genel bir faktöre sahip olduğunu da göstermektedir. Tek faktörlü ölçeklerde açıklanan varyansın \%30 ve daha fazla olması yeterli görülmektedir (Büyüköztürk, 2010b; Çokluk, Şekercioğlu ve Büyüköztürk, 2010). Ölçek maddelerinin faktör yükleri .46 ile .85 arasında hesaplanmıştır. Faktör yük değerinin .45 ya da daha yüksek olması seçim için iyi bir ölçüttür. Fakat bu değerin .30’a kadar indirilebileceği belirtilmiştir (Büyüköztürk, 2010b). Ölçeğin güvenirlik çalışması Cronbach alfa katsayısı ile hesaplanmış ve tek faktörlü yapı için hesaplanan Cronbach alpha iç tutarlık katsayısı .83 olarak bulunmuştur. 


\section{HiMHÖ'nün DFA Sonuçları}

Açımlayıcı faktör analizi sonunda ortaya çıkan faktör yapısının toplanan veriler için ne ölçüde uygun olduğunu belirlemek amacıyla AMOS programı kullanılarak DFA analizi yapılmıştır. HIMHÖ’ye ilişkin DFA sonuçları Tablo 2'de verilmiştir.

Tablo 2. HIMHÖ'ye İlişkin DFA Sonuçları

\begin{tabular}{lllllllll}
\hline$\chi^{2}$ & Sd & $\left(\chi^{2} / \mathbf{s d}\right)$ & RMSEA & CFI & GFI & AGFI & RMR & NFI \\
\hline 22.907 & 14 & 1.636 & .07 & .96 & .94 & .90 & .01 & .92 \\
\hline
\end{tabular}

Doğrulayıcı faktör analizi için uyum indeksleri incelendiğinde ki-kare değerinin serbestlik derecesine oranııın $(22.907 / 14=1.636) 2.5$ 'in altında mükemmel düzeyde bir değere sahip olduğu görülmüştür. Diğer uyum indeksleri incelendiğinde RMSEA= $.07, \mathrm{GFI}=.94, \mathrm{NFI}=.92, \mathrm{CFI}=.96$ olarak bulunmuştur. NFI ve GFI 0.90 ve üzeri olması kabul edilebilir uyumu; CFI indeksinin 0.95 'ten yüksek olması mükemmel uyum değerlerine sahip olduğunu göstermektedir. RMSEA'nın ise $0.05 \leq R M S E A \leq .0 .10$ arasında olması kabul edilebilir uyum düzeyinde olduğunu işaret etmektedir. Doğrulayıcı faktör analizi sonucunda elde edilen uyum iyiliği indeksleri incelendiğinde modelin uyumlu olduğu görülmektedir. Aşağıda ölçeğin faktörleri ve maddelerine ilişkin standartlaştırımış parametre tahminlerinin yer aldığı model Şekil 1 'de sunulmuştur.

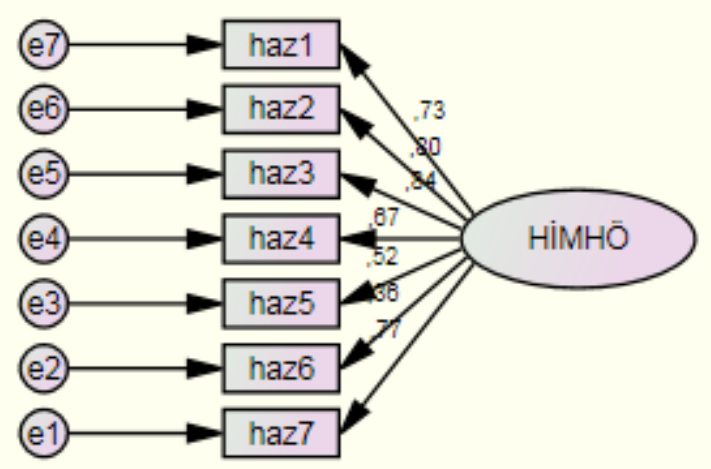

Şekil 1. HIMHÖ'nün DFA sonucu Yol Diyagram

\section{Madde Analizi}

HIMHÖ madde analizleri, madde toplam korelasyonlarına ve \%27'lik üst-alt grup maddelerinin arasındaki farklara bakılarak incelenmiştir. Madde-toplam korelasyonu test maddelerinden alınan puanlar ile testin toplam puanı arasındaki 
ilişkiyi açıklar. Madde toplam korelasyonunun pozitif ve yüksek olması, maddenin benzer davranışları örneklediğini ve testin iç tutarlılığının yüksek olduğunu gösterir. Madde toplam korelasyonu .30 ve üzeri olan maddelerin bireyleri iyi derecede ayırt ettiği söylenebilir (Büyüköztürk, 2010b). HIMHÖ madde toplam korelasyonları ile alt $\% 27$ ve üst \%27'lik grupların madde puanlarının karşılaştııımasına ilişkin t-testi sonuçları Tablo 3'te verilmiştir.

Tablo 3. HIMHÖ madde toplam korelasyonları ile alt $\% 27$ ve üst $\% 27$ 'lik grupların madde puanlarının karşılaştırıımasına ilişkin t-testi sonuçları

\begin{tabular}{|c|c|c|}
\hline Madde no & Madde toplam korelasyonu & $\begin{array}{c}t \\
\text { Korelasyonu (Alt\%27-Üst\%27) }\end{array}$ \\
\hline 1 & .76 & $4.58^{\text {tht }}$ \\
\hline 2 & .76 & $2.51^{\star \star *}$ \\
\hline 3 & .84 & $3.88^{* * *}$ \\
\hline 4 & .75 & $3.19^{* * *}$ \\
\hline 5 & .56 & $3.51^{* \star *}$ \\
\hline 6 & .58 & $2.39^{* * *}$ \\
\hline 7 & .78 & $4.05^{\star \star *}$ \\
\hline
\end{tabular}

Tablo 3 incelendiğinde HiMHÖ'nün madde toplam korelasyonlarının .56 ile .84 arasında değişiklik gösterdiği ve t-değerlerinin anlamlı olduğu saptanmıştır $(p<.001)$. Madde toplam korelasyonlarının .30'dan büyük olması ve $\% 27^{\prime}$ lik alt-üst grup madde karşılaşıımaları için kullanılan t-testi sonuçlarının tüm maddeler için anlamlı çıkması ölçekteki maddelerin güvenirliklerinin yüksek olduğunu ve aynı davranışları ölçmeye yönelik olduklarını göstermektedir (Büyüköztürk, 2010b).

\section{Tartışma ve Sonuç}

Bu çalışmada Mesleki Haz Ölçeği hakemlere uyarlanarak geçerlik ve güvenirlik çalışması yapılmıştır. Verilerin faktör analizine uygun olup olmadığı KMO katsayısı ve Barlett (Sphericity) Küresellik testi ile incelenebileceği belirtilmiştir (Büyüköztürk, 2010). Bazı araştırmacılar faktör analizi için KMO katsayısının örneklem büyüklüğü için değerinin .80 - .90 arasında olmasının iyi ve Barlet sphericity testinin .05 düzeyinde anlamlı çıkması gerektiğini belirtmektedir (Çokluk ve ark., 2010; Leech ve ark., 2005). KMO katsayısının .85 ve Barlett Sphericity testi sonucunun $\mathrm{X} 2=295,474, \mathrm{df}=21,(p<.00)$ istatistiksel olarak anlamlı bulunması verilerin faktör analizine uygun olduğunu göstermektedir. 
Açımlayıcı faktör analizi sonucunda toplam açıklanan varyansın \%50.59 olduğu saptanmıştır. Bu bulgu ölçeğin genel bir faktöre sahip olduğunu da göstermektedir. Tek faktörlü ölçeklerde açıklanan varyansın $\% 30$ ve daha fazla olması yeterli görülmektedir (Büyüköztürk, 2010; Çokluk ve ark., 2010). Ölçek maddelerinin faktör yükleri .46 ile .85 arasında hesaplanmıştır. Faktör yük değerinin .45 ya da daha yüksek olması seçim için iyi bir ölçüttür. Fakat bu değerin .30'a kadar indirilebileceği belirtilmiştir (Büyüköztürk, 2010). Ölçeğin güvenirlik çalışması Cronbach alfa katsayısı ile hesaplanmış ve tek faktörlü yapı için hesaplanan Cronbach alpha iç tutarlık katsayısı .83 olarak bulunmuştur.

Doğrulayıcı faktör analizi daha önceden tanımlanmış ve sınırlandırılmış bir yapının, bir model olarak doğrulanıp doğrulanmadığının test edildiği bir analizdir (Çokluk ve ark., 2010). Doğrulayıcı faktör analizi sonuçlarını geçerli kabul edebilmek için modele ait uyum iyiliği indekslerinin yeterlilik göstermesi gerekmektedir. GFI, NFI ve CFI 0.90'dan büyük değerlerde olması yeterli düzeyde uyumun olduğu, değerlerin 0'a yaklaşmasının kötü, 1'e yaklaşmasının mükemmel uyum gösterdiği, RMSEA ise 0.05 'ten küçük olmasının iyi uyumu, .10'Un altında olması ise kabul edilebilir bir uyum iyiliğini, ki-kare/serbestlik derecesi uyum indeksinin 5'ten küçük olması orta düzeyde, 2.5’ten küçük olması mükemmel uyumu göstermektedir (Çokluk ve ark., 2010; Kline, 2005; Schumacker ve Lomax, 2004; Şimşek, 2007; Tabachnick ve Fidell, 2007; Yılmaz ve Çelik, 2009).

HİMHÖ için doğrulayıcı faktör analizi uyum indeksleri incelendiğinde ki-kare değerinin serbestlik derecesine oranının (22.907/14=1.636) 2.5'in altında mükemmel düzeyde bir değere sahip olduğu görülmüştür. Diğer uyum indeksleri incelendiğinde RMSEA $=.07, \mathrm{GFI}=.94, \mathrm{NFI}=.92, \mathrm{CFI}=.96$ olarak bulunmuştur. NFI ve GFI 0.90 ve üzeri olması kabul edilebilir uyumu; CFI indeksinin 0.95 'ten yüksek olması mükemmel uyum değerlerine sahip olduğunu göstermektedir. RMSEA'nın ise $0.05 \leq R M S E A \leq .0 .10$ arasında olması kabul edilebilir uyum düzeyinde olduğunu işaret etmektedir. Doğrulayıcı faktör analizi sonucunda elde edilen uyum iyiliği indeksleri incelendiğinde modelin uyumlu olduğu görülmektedir.

HIMHÖ madde analizleri, madde toplam korelasyonlarına ve \%27'lik üst-alt grup maddelerinin arasındaki farklara bakılarak incelenmiştir. Madde-toplam korelasyonu test maddelerinden alınan puanlar ile testin toplam puanı arasındaki ilişkiyi açıklar. Madde toplam korelasyonunun pozitif ve yüksek olması, maddenin benzer davranışları örneklediğini ve testin iç tutarlılığının yüksek olduğunu gösterir. 
Madde toplam korelasyonu .30 ve üzeri olan maddelerin bireyleri iyi derecede ayırt ettiği söylenebilir (Büyüköztürk, 2010).

HIMHÖ'nün madde toplam korelasyonlarının .56 ile .84 arasında değişiklik gösterdiği ve t-değerlerinin anlamlı olduğu saptanmıştır $(p<.001)$. Madde toplam korelasyonlarının .30'dan büyük olması ve \%27'lik alt-üst grup madde karşılaştırmaları için kullanılan t-testi sonuçlarının tüm maddeler için anlamlı çıkması ölçekteki maddelerin güvenirliklerinin yüksek olduğunu ve aynı davranışları ölçmeye yönelik olduklarını göstermektedir.

Yapılan analizler sonucunda elde edilen veriler, HİMHÖ ölçeğinin hakemlerin mesleki haz düzeylerini ölçmede geçerli ve güvenilir olduğunu göstermektedir. HIMHÖ 7 madde ve tek boyuttan oluşmaktadır. Ölçekte ters kodlanan madde bulunmamaktadır. Ölçekten alınan puan arttıkça hakemlik mesleğinden alınan haz da artmaktadır.

\section{Kaynaklar}

Büyüköztürk, Ş. (2010a). Bilimsel araştırma yöntemleri (5. Baskı). Ankara: Pegem Akademi.

Büyüköztürk, Ş. (2010b). Sosyal bilimler için veri analizi el kitabı (11. Baskı). Ankara: Pegem Akademi.

Çokluk, Ö., Şekercioğlu, G. ve Büyüköztürk, Ş. (2010). Sosyal bilimler için çok değişkenli istatistik. Ankara: Pegem.

Ekmekçi, R. (2008). Basketbol hakemlerinin stres kaynakları ile stresle başa çıkma yöntemlerinin tesbiti ve önleyici yönetsel uygulamaların geliştirilmesi(Unpublished doctoral dissertation). Abant İzzet Baysal Üniversitesi, Bolu.

Ekmekçi, R. (2016). Hakemlikte psikolojik hazırlık. Ankara: Detay Yayıncılık.

Erdoğan, O. (2013). İlköğretim öğretmenlerinin öz yeterlilik ve başarı algılarında yordayıcı olarak akademik iyimserlik, umut ve mesleki haz. Yayımlanmamış yüksek lisans tezi. Gazi Üniversitesi, Eğitim Bilimleri Enstitüsü, Ankara.

Eroğlu, A. (2009). Faktör Analizi. Ş. Kalaycı (Ed.), SPSS Uygulamalı çok değişkenli istatistik teknikleri (ss.321-331). Ankara: Asil Yayın Dağıtım.

Guillén, F., \& Feltz, D. L. (2011). A conceptual model of referee efficacy. Frontiers in psychology, 2, 25. 
Hoy, W. K., \& Tarter, C. J. (2011). Positive psychology and educational administration: An optimistic research agenda. Educational Administration Quarterly, 47(1), 427- 447.

Josepshon, M., \& Vingard, M. (2007). Zest for work? Assessment of enthusiasm and satisfaction with the present work situation and health - A 1.5-year follow-up study. Work, 29, 225-231.

Karaçam A. \& Pulur A. (2016). Identification the Relation between Active Basketball Classification Referees' Empathetic Tendencies and Their Problem Solving Abilities. Universal Journal of Educational Research, 4 , 1912 - 1917.

Kline, R. B. (2005). Principles and practice of structural equations modeling. New York: Guilford.

Leech, N. L., Barrett, K. C., \& Morgan, G. A. (2005). SPSS for intermediate statistics: Use and interpretation (2nd ed.). New Jersey: Lawrence Erlbaum Ass.

Lent, R. W., \& Brown, S. D. (2006). Integrating person and situation perspectives on work satisfaction: A social-cognitive view. Journal of Vocational Behavior, 69, 236-247.

Lent, R. W., Nota, L., Soresi, S., Ginevra, M. C., Duffy, R. D., \& Brown, S. D. (2011). Predicting the job and life satisfaction of Italian teachers: Test of a social cognitive model. Journal of Vocational Behavior, 79, 91-97.

Myers, N. D., Feltz, D. L., Guillén, F., \& Dithurbide, L. (2012). Development of, and initial validity evidence for, the Referee Self-Efficacy Scale: A multistudy report. Journal of sport and Exercise Psychology, 34(6), 737-765.

Park, N., \& Peterson, C. (2010). The urban psychology of character strengths. American Psychological Association, 65(6), 535-547.

Peterson, C., \& Seligman, M. E. P. (2004). Character strengths and virtues: A handbook of classification. New York, NY: Oxford University.

Peterson, C., Park, N., Hall, N., \& Seligman, M. E. P. (2009). Zest and work. Journal of Organizational Behavior, 30(2), 161-172.

Raykov, T., \& Marcoulides, G. A. (2000). A first course in structural equation modeling. New Jersey: Lawrence Erlbaum Associates.

Schumacker, R. E., \& Lomax, R. G. (2004). A beginner's guide to structural equation modeling. New Jersey: Lawrence Erlbaum Ass. 
Sezgin, F., \& Erdogan, O. (2015). Academic optimism, hope and zest for work as predictors of teacher self-efficacy and perceived success. Educational Sciences: Theory \& Practice, 15(1), 7-19.

Şimşek, Ö. F. (2007). Yapısal eşitlik modellemesine giriş: Temel ilkeler ve lisrel uygulamaları. Ankara: Ekinoks Yayınclık.

Tabachnick, B. G., \& Fidell, L. S. (2007). Using Multivariate Statistics. Boston: Allyn and Bacon.

Thomson, B. (2004). Exploratory and confirmatory factor analysis. Washington: APA.

Tuero, C., Tabernero, B., Marquez, S., \& Guillen, F. (2002). Análisis de los factores que influyen en la práctica del arbitraje [Analysis of the factors affecting the practice of refereeing]. SCAPE, 1(1), 7-16.

Weinstein, N., \& Ryan, R. M. (2009). Vitality. In S. J. Lopez (Eds.), The encyclopedia of positive psychology (pp. 1023-1025). Singapore: Blackwell.

Yılmaz, V. ve Çelik, H. E. (2009). Lirsel ile yapısal eşitlik modellemesi-1. Ankara: Pegem Yayıncılık. 